\section{DISCUSSION}

Both of our patients presented with arthritis earlier than previously reported in SLE-sickle hemoglobinopathy. The arthritis was nondeforming and not associated with painful sickle crises, infection, or radiographic evidence of aseptic necrosis of bone. The 10-year-old girl with sickle trait presented with other manifestations of SLE including alopecia, butterfly rash, mucous membrane ulcerations and hypocomplementemia and has had SLE involvement of every organ system during 8 years, while the $4 \frac{1}{2}$ year-old girl with homozygous sickle cel]. disease presented with joint involvement and fever without other manifestations of SLE.

Systemic lupus erythematosus is rare in children less than 10 years of age $\mathrm{e}^{0.10}$ and the association of SLE with sickle hemoglobinopathy has not been previously reported in children. Whether the presence of sickle hemoglobin influenced the onset of early inflammatory arthritis in one case or the severity of an immunemediated systemic disease in the other case merits further investigation. Our findings suggest that patients with sickle hemoglobinopathy and arthritis should be thoroughly evaluated for immunologic causes of arthritis.

\section{REFERENCES}

1. Schumacher HR, Andrews R, and McLaughlin G: Arthropathy in sickle cell disease, Ann Intern Med 78:203, 1973.

2. Schumacher HR, et al: Chronic synovitis with early cartilage destruction in sickle cell disease, Ann Rheum Dis 36:413, 1977.

3. Worrall VT, et al: Sickle cell dactylitis, J Bone Joint Surg 58A:1161, 1976.

4. Nelson JD: Sickle-cell disease and bacterial bone and joint infection, N Engi J Med 292:534, 1975.

5. Sears DA: Morbidity of sickle cell trait, Am J Med 64:1021, 1978.

6. Palmer DW, et al: Septic arthritis and Reiter's syndrome in sickle cell disorders, South Med J 69:902, 1976.

7. Hanissian A, and Silverman A: Arthritis of sickle cell anemia, South Med J 67:28, 1974.

8. Wilson WA, et al: SLE and sickle cell anemia, Br Med $\mathbf{J}$ 1:813, 1976.

9. Norris DG, Colon AR, and Stickler GB: Systemic lupus erythematosus in children, Clin Pediatr 16:774, 1977.

10. Walravens PA, and Chase HP: The prognosis of childhood systemic lupus erythematosus, Am J Dis Child 130:929, 1976.

\title{
3-Hydroxy-3-methylglutaryl coenzyme A lyase deficiency: Postnatal management following prenatal diagnosis by analysis of maternal urine
}

\author{
Marinus Duran, Ph.D., Ruud B.H. Schutgens, Ph.D.,* Arnold Ketel, M.D., Hugo Heymans, M.D., \\ Marja W.J. Berntssen, Dirk Ketting, and Sybe K. Wadman, Ph.D.,** Amsterdam and Utrecht, \\ The Netherlands
}

Two PATIENTS with a deficiency of 3-hydroxy-3methylglutaryl coenzyme A (HMG-CoA) lyase have been described. ${ }^{1.2}$ This enzyme catalyzes the final step of leucine degradation and plays a key role in ketone body formation. Clinically the defect is associated with metabolic acidosis and hypoglycemia. The biochemical diagnosis is based on the finding of abnormal organic aciduria with highly increased urinary excretion of 3-hydroxy-

From the Paediatric Clinic, University Hospital of Amsterdam and University CHitdren's Hospital "Het Wilhelmina Kinderziekenhuis."

${ }^{*}$ Reprint address: Paediatric Clinic, University Hospital of Amsterdam, Binnengastiktis. Grimburgwal 10,1012 GA

Amsterdam. The Netherlands.

** Supported by "Het Praeventiefonds," The Hague. 3-methylglutarie acid, 3-methylglutaconic acid, 3methylglutaric acid, and 3-hydroxyisovaleric acid. ${ }^{3+}+$ The enzyme can be measured in various tissues, including leukocytes ${ }^{5}$ and fibroblasts. ${ }^{6}$ Following our experiences
Abbreviations used
HMG: 3-hydroxy-3-methylglutaric acid
HMG-CoA: 3-hydroxy-3-methylglutaryl coenzyme A

with a patient who died in an attack of hypoglycemia due to HMG-CoA lyase deficiency, ${ }^{2}$ we counseled the parents about the genetic aspects of this disease. The mother informed us of her next pregnancy at the twenty-third week of gestation. We then investigated the possibility of antenatal diagnosis by a non-invasive technique, i.e., quantitative analysis of organic acids in maternal urine. In 


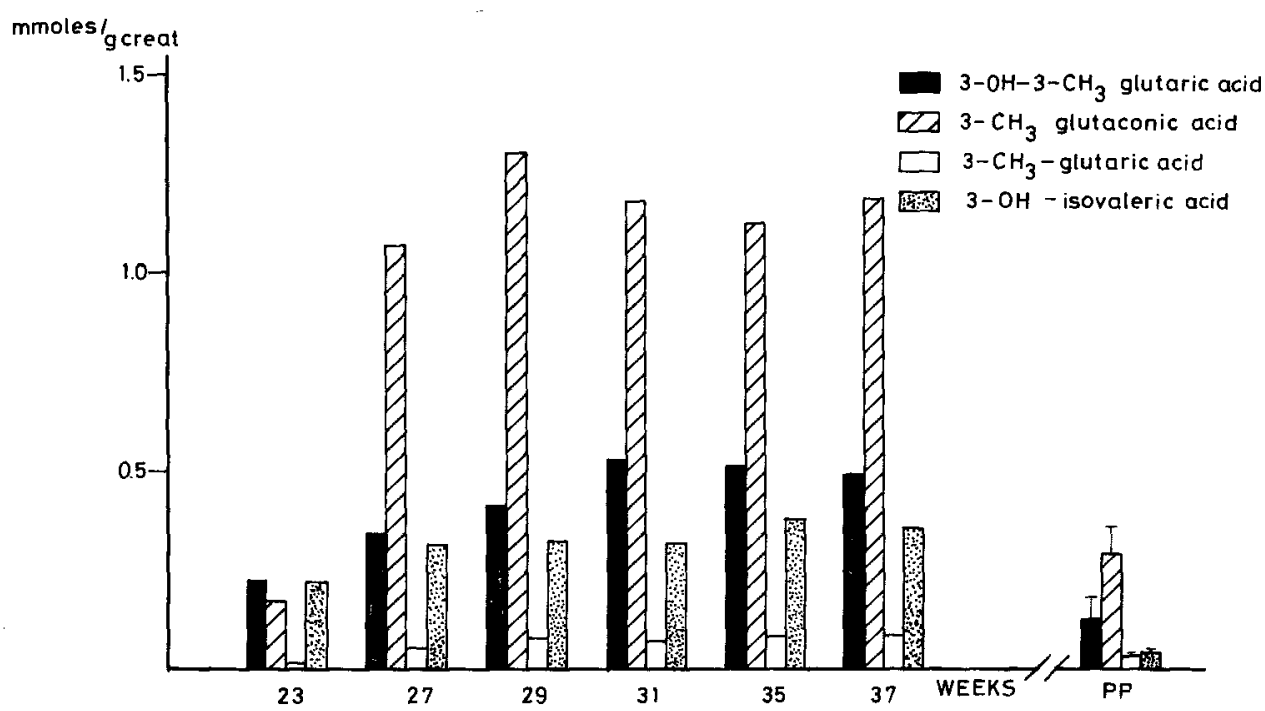

Figure. Urinary leucine metabolites of mother during pregnancy at risk.

Table. Organic acid in urine and serum from patient with 3-hydroxy-3-methylglutaryl-CoA lyase deficiency.

\begin{tabular}{|c|c|c|c|c|c|c|c|c|}
\hline & \multicolumn{2}{|r|}{$H M G$} & \multicolumn{2}{|c|}{ 3-Methylglutaconic acid } & \multicolumn{2}{|c|}{ 3-Methylglutaric acid } & \multicolumn{2}{|c|}{ 3-hydroxy-isovaleric acid } \\
\hline & mmol/l & mmol/gm creat & mmol/l & $\mathrm{mmol} / \mathrm{gm}$ creat & $\mathrm{mmol} / \mathrm{l}$ & $\mathrm{mmol} / \mathrm{gm}$ creat & $\mathrm{mmol} / \mathrm{l}$ & mmol/gm creat \\
\hline \multicolumn{9}{|l|}{ Urine } \\
\hline Day 1 & 2.37 & 6.35 & 1.05 & 4.99 & 0.16 & 0.75 & 0.03 & 0.16 \\
\hline Day 2 & 50.29 & 65.32 & 72.22 & 93.79 & 4.64 & 6.02 & 3.23 & 3.89 \\
\hline Day 14 & 1.35 & 24.58 & 2.62 & 47.73 & 0.16 & 2.86 & 0.44 & 8.01 \\
\hline $1.5 \mathrm{mo}$ & 3.68 & 27.30 & 6.51 & 48.19 & 0.45 & 3.29 & 1.47 & 10.85 \\
\hline $2.5 \mathrm{mo}$ & 1.30 & 23.57 & 1.99 & 36.24 & 0.18 & 3.36 & 1.23 & 22.34 \\
\hline $3.5 \mathrm{mo}$ & 2.17 & 18.10 & 5.73 & 47.74 & 0.32 & 2.62 & 1.11 & 9.25 \\
\hline $6 \mathrm{mo}$ & 1.80 & 18.05 & 3.53 & 35.34 & 0.25 & 2.48 & 0.99 & 9.87 \\
\hline \multicolumn{9}{|l|}{ Serum } \\
\hline Patient & $\operatorname{tr}$ & & $\operatorname{tr}$ & & nd & & 0.29 & \\
\hline Control & nd & & nd & & nd & & nd & \\
\hline
\end{tabular}

nd $=$ Not detectable; $\operatorname{tr}=$ trace $($ less than $0.01 \mathrm{mmol} / \mathrm{l})$.

this report we present the results of this approach, as well as the final outcome of the pregnancy and attempted treatment in the first months of life.

\section{METHODS}

HMG-CoA lyase (E.C. 4.1.3.4.) activity was measured in leukocytes and in homogenate of placenta by the radiochemical procedure of Clinkenbeard et al. ${ }^{\top}$ Malate dehydrogenase was measured as a control enzyme. ${ }^{8}$ Organic acids were determined as trimethylsilyl derivatives, as described previously.

\section{CASE REPORTS}

In this Moroccan family, two children died elsewhere during their first year of life, probably after a dietary change from breast milk to corn and cow milk had been made. Three sibs are healthy. The sixth child, who has been described by us before, ${ }^{2}$ had severe hypoglycemia and metabolic acidosis in the neonatal period. After correction of his blood glucose concentration he developed well initially, but at the age of 6 months he died suddenly during an attack of extreme hypoglycemia (blood glucose concentration less than $1.8 \mathrm{mg} / \mathrm{dl}$ ). HMG-CoA lyase deficiency was diagnosed post mortem by identification of the organic acids in the patient's urine and by enzymic studies.

The mother's next pregnancy was uncomplicated and resulted in the delivery of a mature male neonate (birth weight $3,500 \mathrm{gm}$ ). Physical examination revealed no abnormality. The suspected HMG-CoA lyase deficiency was confirmed by demonstration of the characteristic organic aciduria ${ }^{4}$ in the first voided urine (Table) and by the finding of extremely low HMG-CoA lyase activity $^{7}$ in the patient's leukocytes on the first day of life. He was 
breast-fed up to the age of 7 months with a regular oral supplementation of glucose $(10 \% \mathrm{w} / \mathrm{v})$ feedings $(7 \times 30 \mathrm{ml} /$ day $)$. On this regimen no hypoglycemia was observed. The only biochemical abnormality observed was a persistent mild and compensated metabolic acidosis, apparently caused by the accumulation of abnormal leucine metabolites.

The patient is developing well clinically during the first 7 months of life. He is growing now into the seventy-fifth percentile for weight and length, and his psychomotor development is normal.

\section{RESULTS}

The analysis of organic acids in the mother's urine, sampled in the twenty-third week of pregnancy, showed a considerable excretion of HMG and 3-methylglutaconic acid. The amounts excreted, as well as those of 3methylglutaric and 3-hydroxyisovaleric acids, increased steadily during the following weeks (Figure). However, a constant level of excretion was reached at the thirty-first week of gestation and no further increase occurred thereafter. The baby was born at term.

The first voided urine sample of the infant contained large amounts of the leucine metabolites (Table), characteristic of the homozygous state of HMG-CoA lyase deficiency. No measurable HMG-CoA lyase activity could be detected in leukocytes isolated from cord blood and in the placenta. The excretion of leucine metabolites increased further after the child got his first proteincontaining feedings, but leveled off later (Table).

In urine from the father and from the three healthy sibs, only trace amounts of the characteristic organic acids could be detected. HMG-CoA lyase activity was also measured in leukocytes from the parents. A recessive mode of inheritance was demonstrated by the finding of intermediate enzymic activities in the mother (5.1) and father (10.8) in comparison with controls, who had 16.4 to $27.5 \mathrm{nmoles} / \mathrm{minute} / \mathrm{mg}$ protein.

\section{DISCUSSION}

Deficiency of hepatic $\mathrm{HMG-CoA}$ lyase will result in defective intramitochondrial cleavage of $\mathrm{HMG}-\mathrm{CoA}$ to acetoacetate and acetyl-CoA. The resulting shortage of glucose-sparing ketone bodies will induce hypoglycemia, whereas the accumulation of leucine metabolites will cause severe metabolic acidosis. Four patients with HMGCoA lyase deficiency are known at present, including our two Moroccan patients. The remaining patients are an Australian boy ${ }^{1}$ and a girl of Portưgúese descent (Dr. D.Leupold, Ulm, GFR, personal communication). Recently a girl of Pakistani origin with HMG-aciduria was described. ${ }^{9}$ Although the frequency of this disease is considered to be very low, a number of cases may have been missed in neonates dying of incurable acidosis and hypoglycemia.

Although prenatal diagnosis by HMG-CoA lyase assay in cultured amniotic cells is theoretically possible, no such attempt has been made at the present time. Here we have described antenatal diagnosis of this disease by analyzing metabolites in maternal urine. However, prediction of an affected fetus by this technique may not be possible until the second half of pregnancy, as the excretion of leucine metabolites was not significantly different from the basal excretory level in the mother, measured several weeks after delivery. Clearly the advantage of this technique is its non-invasiveness. The early diagnosis facilitates immediate treatment with glucose supplements and correction of acidosis after delivery.

We think that, at least in treatable disorders, this approach may be as successful as prenatal diagnosis by amniocentesis. HMG-CoA lyase deficiency may be considered treatable because at least two of four patients are physically thriving. One of the patients died before a diagnosis was available, and correct dietary measures could not be taken.

We have demonstrated that the heterozygous state of HMG-CoA lyase is expressed in the activity of this enzyme in leukocytes, proving a recessive mode of inheritance. It remains unclear whether heterozygotes can be traced by gas chromatographic analysis of their urine. We found definitely abnormal excretory levels in the mother, whereas the father's excretion of leucine metabolites was normal. Leucine loading, which might provide better discrimination between heterozygotes and normal subjects, was not allowed in this family. Although the exact mechanism of the extreme hypoglycemia in HMG-CoA lyase-deficient patients is not known, we plan to restrict leucine in the diet of this patient after the breast feeding period to prevent possible clinical deterioration.

We thank the midwives Mrs. Sam and Ruhland for their intensive cooperation; Prof. Dr. W. H. H. Tegelaers for his advice and critical comments; Ir. H. A. Veder and R. Balkenende for aminoacid analyses; and Mrs. P. Zwaal and P. Kok for preparing the manuscript.

\section{REFERENCES}

1. Faull K, Bolton P, Halpern B, Hammond J, Danks DM, 'Hähnel R, Wilkinson SP, Wysocki SJ, and Masters PL: Patient with defect in leucine metabolism, $N$ Engl J Med 294:1013, 1976.

2. Schutgens RBH, Heymans H, Ketel A, Veder HA, Duran $M$, Ketting D, and Wadman SK: Lethal hypoglycemia in a child with a deficiency of 3-hydroxy-3-methyl glutarylcoenzyme A lyase, J Pediatr 94:89, 1979.

3. Wysocki SJ, Wilkinson SP, Hähnel R, Wong CYB, and Panegyres PK: 3-hydroxy-3-methylglutaric aciduria, com- 
bined with 3-methylglutaconic aciduria, Clin Chim Acta 70:399, 1976.

4. Duran M, Ketting D, Wadman SK, Jakobs C, Schutgens $\mathrm{RBH}$, and Veder HA: Organic acid excretion in a patient with 3-hydroxy-3-methylglutaryl-CoA lyase deficiency: facts and artefacts, Clin Chim Acta 90:187, 1978.

5. Wysocki SJ, and Hähnel R: 3-hydroxy-3-methylglutaric aciduria: 3-hydroxy-3-methylglutaryl-coenzyme A lyase levels in leucocytes, Clin Chim Acta 73:373, 1976.

6. Wysocki SJ, and Hähnel R: 3-Hydroxy-3-methylglutaric aciduria: deficiency of 3-hydroxy-3-methylglutaric coenzyme A lyase, Clin Chim Acta 71:349, 1976.
7. Clinkenbeard KD, Reeds WD, Mooney RA, and Lane MD: Intracellular localization of 3-hydroxy-3-methylglutaryl coenzyme A cycle enzymes in liver, J Biol Chem 250:3108, 1975.

8. Bergmeier HA: in Methoden der Enzymatischen Analyse ed 3, Weinheim, FRG, 1974, Verlag Chemie, p. 649.

9. Leonard JV, Seakins JWT, and Griffin NK: $\beta$-hydroxy$\beta$-methylglutaric aciduria presenting as Reye's syndrome, Lancet 1:680, 1979.

\section{Kinky hair, photosensitivity, broken eyebrows and eyelashes, and nonprogressive mental retardation}

Raul Calderon, M.D.,* and Nelly Gonzalez-Cantu, M.D., Monterrey, Mexico

MACRO- AND MICROSCOPIC hair abnormalities of different types, such as stubby, coarse, sparse or fragile hair, twisted hair shaft (pili torti), segmental narrowing (monilethrix), or hair shaft fractures with ends with a brushlike appearance (trichorrhexis) have been reported in several disorders. ${ }^{1-4}$ We describe here two members of a family resulting from a consanguineous marriage who had kinky hair, photosensitivity, broken eyebrows and eyelashes, and nonprogressive mental retardation without detectable metabolic abnormality.

\section{CASE REPORT}

Patient 1. This white girl was first seen at the age of 14 years because of mental retardation. She was born of a fourth pregnancy after 37 weeks' gestation. The parents were first cousins. The delivery was uneventful, birth weight was $3,000 \mathrm{gm}$, and there were no problems in the immediate neonatal period. At birth, she had abundant and apparently normal hair. By the age of 3 months, however, she had lost all of her hair and was completely bald. Since then, the scalp hair appears sparse, coarse, dry, and easily broken, It breaks off before reaching 1 to $1.5 \mathrm{~cm}$ of length.

She walked at the age of 2 years, spoke isolated words at 6 , and made phrases at 8 years. At school, she repeated the first and third grades on three occasions.

She has had photosensitivity to sunshine since infancy, developing erythema and dermatitis in the exposed areas of the skin,

From the Neurological Center for Children and Adolescents, University of Monterrey and the Sacial Security Specialty Hospital.

*Reprint address: Aleutianas 459, Col. Vista Hermosa, Monterrey. México. mainly over the ciliary regions and eyelids. This also increases the tendency of the scalp hair, eyebrows, and eyelashes to break. She has had frequent and recurrent infections.

Family history. The parents are first cousins; both are normal. She has an older sister who is normal and two sisters with similar clinical manifestations. One died of purulent meningitis at 6 years of age, and the other is 19 years of age; her development and examination were identical to these reported in this patient.

Physical examination. At the age of 14 years, the examination revealed an alert, attentive, pleasant girl, with a height of $141 \mathrm{~cm}$, weight of $30 \mathrm{~kg}$, and a head circumference of $49.5 \mathrm{~cm}$ (under the third percentile). The scalp hair was brown, sparse, dry, coarse, short, (the longest was $1 \mathrm{~cm}$ ), slightly curly, fragile, and easily broken. The eyebrows and eyelashes were broken to a couple of millimeters from the skin; they also looked sparse, dry, and coarse, and the skin in these areas was erythematous and slightly swollen (Figure). The hair on the limbs also appeared to be broken off 1 or $2 \mathrm{~mm}$ from the skin. Microscopically, the hair showed twisting of the hair shaft (pili torti), segmental narrowing (monilethrix), and hair shaft fractures with ends with a brushlike appearance (trichorrhexis).

The fundi were normal. All the cranial nerves were intact. There was normal muscle tone. The deep tendon reflexes were normal with bilateral flexor plantar responses. There was no sensory deficit to superficial or deep stimuli.

Psychometric studies with the Wechsler Intelligence Scale for Children revealed a verbal IQ of 58, a performance IQ of 58 and a total IQ of 54.

Laboratory data. Complete blood count and blood chemistry determinations, including tests for glucose, urea nitrogen, creatinine, potassium, calcium, phosphorus, SGOT, bilirubin, alkaline and acid phosphatase, PBI, cholesterol, serum protein electrophoresis and amino acid analysis all showed normal results. 